\title{
Reutilizando materiales en las construcciones de los siglos VII-X. ¿Una posibilidad o una necesidad? ${ }^{1}$
}

\author{
María de los Ángeles Utrero Agudo ${ }^{2}$ \\ Instituto de Historia, CCHS-CSIC \\ mariaangeles.utrero@cchs.csic.es \\ Isaac SASTRE DE DIEGO \\ Universidad de Oxford (contratado postdoctoral FECYT) \\ isaac.sastre-dediego@history.ox.ac.uk
}

La reutilización de materiales constructivos (piedra, ladrillo y madera, esencialmente), decorativos y litúrgicos (principalmente altares) es una práctica habitual en los proyectos arquitectónicos de época tardoantigua y altomedieval de todo el área mediterránea. De igual modo se constata en las construcciones coetáneas de la Península Ibérica, principalmente aquellas de carácter eclesiástico.

Lejos de evaluar los aspectos visuales o simbólicos de la reutilización, pretendemos analizar dicho proceso dentro de un contexto productivo y tecnológico. Los análisis arqueológicos realizados en la última década en algunas iglesias tardoantiguas y altomedievales ${ }^{3}$ ofrecen nuevos y significativos datos al respecto. Este trabajo selecciona algunos de ellos con la intención de tratar un tema frecuentemente visitado por la investigación extranjera, principalmente la referente a la arquitectura romana, pero aún escasa en nuestro ámbito peninsular. Por ello, tampoco pretendemos crear un patrón de este fenómeno, si es que esto es posible ${ }^{4}$, pero sí llamar la atención sobre su complejidad y riqueza, así como sobre la necesidad de afrontar su estudio desde

\footnotetext{
1 Agradecemos las sugerencias y comentarios realizados al texto por L. Caballero Zoreda (Instituto de Historia, CCHS-CSIC), director del proyecto de investigación "Análisis Arqueológico de la Arquitectura Altomedieval en Asturias: prospección, estratigrafía y cronotipología. HUM 2007-61417/HIST”, financiado por el Ministerio de Educación y Cultura, dentro del cual se inscribe este trabajo.

2 Investigadora contratada Ramón y Cajal, Grupo de investigación Arqueología de la Arquitectura, Línea de investigación Historia Social del Poder, IH-CCHS (CSIC), Madrid.

3 Síntesis en Ma Á. UTRERO, "Late Antique and Early Medieval Hispanic Churches and the Archaeology of Architecture: Revisions and Reinterpretation of Constructions, Chronologies and Contexts", Journal of Medieval Archaeology, 54 (2010), pp. 1-33.

4 Como apuntan algunos trabajos clásicos en la arquitectura italiana: F. W. DEICHMANN, "Säule und Ordnung in der frühchristlichen Architektur", Römische Mitteilungen, 55 (1940), pp. 114-130; Ibídem, "Il materiale di spoglio nell'architettura tardoantica", XXIII Corso di Cultura sull'Arte Ravennate e Bizantina, Ravenna 1976, Rávena, 1976, pp. 131-146. Para la arquitectura altomedieval hispánica: E. VERGNOLLE, "Le rôle architectural des chapiteaux du haut Moyen Age Occidental: remplois, paires, groupes”, CH. EWERT, P.
} 
otros parámetros. El objetivo principal es valorar la relación de la reutilización de materiales con la capacidad productiva y tecnológica de los talleres constructivos y decorativos responsables de las obras y con la de los patronos que las financian.

\section{UNA BREVE HISTORIA DE LA INVESTIGACIÓN}

La abundante bibliografía sobre el tema de la reutilización ${ }^{5}$ entre los siglos IV y X, centrada principalmente en la arquitectura italiana y más concretamente romana, viene a coincidir en la propuesta de un modelo que distingue nítidamente dos fases en el fenómeno de la reutilización para el Mediterráneo occidental.

La primera fase se desarrolla en la Tardoantigüedad (siglos IV-VII) y se caracteriza por la puesta en práctica de los principios de la paridad y la simetría por tamaños y colores $^{6}$, dando lugar a lo que se ha llamado la estética de la varietas (mezcla de estilos y órdenes) con un carácter simbólico ${ }^{7}$. Se rompe la precedente uniformidad y homogeneidad de los órdenes clásicos ${ }^{8}$, colocándose piezas significativas (decoraciones principalmente) de acuerdo a los principios indicados. Este reempleo también se ha considerado un fenómeno ideológico de recuperación, preservación y apropiación del valor de lo expoliado 9 , habiendo sido el emperador Constantino y sus arquitectos los grandes impulsores. Otros investigadores, por el contrario, han destacado su papel como recurso constructivo que refleja la pobreza de medios en obras poco cuidadas y precipitadas ${ }^{10}$, donde el expolio permitiría ahorrar tiempo y dinero ${ }^{11}$.

La segunda fase (siglos VIII-X) supone, frente a la anterior, la pérdida de ese "desorden ordenado". Se prescinde del canon y de la proporción, y será práctica común la combinación de piezas reutilizadas con otras talladas ex novo. No se busca una unidad ni una armonía, reinando la heterogeneidad en la selección y colocación de los

CRESSIER y J. ZOZAYA (eds.), Coloquio Internacional de capiteles corintios prerrománicos e islámicos (ss. VI-XII d. C.), Madrid, 1990, pp. 53-69.

5 Sobre el concepto de spolia y su evolución en la historiografía especializada: D. KINNEY, "Rape or Restituion of the Past? Interpreting Spolia", S. S. SCOTT (ed.), The Art of Interpreting, Papers in Art History from the Pennsylvania State University, vol. IX, Pennsylvania, 1995, pp. 53-68.

6 F. W. DEICHMANN, op. cit., 1940.

7 Ibidem, Die Spolien in der spätantiken Architektur, Verlag der Bayerischen Akademie der Wissenchaften, Heft 6, Munich, 1975; B. BRENK, "Spolia from Constantine to Charlemagne: Aesthetics versus Ideology", Dumbarton Oaks Papers, 41 (1987), pp. 103-110; Ibidem, "Spolien und ihre Wirkung auf die Ästhetik der varietas. Zum Problem alternierender Kapitelltypen”, J. POESCHKE (ed.), Antike Spolien in der Architektur des Mittelalters und der Reinassance, Munich, 1996, pp. 49-92.

8 H. BRANDENBURG, "Die Verwendung von Spolien und originales Werkstücken in der spätantiken Architektur", J. POESCHKE (ed.), Antike Spolien in der Architektur des Mittelalters und der Reinassance, Munich, 1996, pp. 11-48 (p. 30).

9 R. KRAUTHEIMER, Studies in Early Christian, Medieval, and Renaissance Art, Londres, 1969 y B. BRENK, op. cit., 1987.

10 F. LOT, The End of the Ancient World and the Beginnings of the Middle Ages, Nueva York, 1965, pp. 136-137.

11 P. PENSABENE, "Reimpiego dei marmi antichi nelle chiese altomedievali a Roma", G. BORGHINI (ed.), Marmi antichi, Roma, 1989, pp. 55-64, quien además añade a las anteriores explicaciones la existencia de un sentido litúrgico para los mármoles antiguos reutilizados en iglesias de Roma. 
elementos. Esto se evidencia, por ejemplo, en el empleo de columnas cuyo diámetro no concuerda con los capiteles, en las diferentes alturas de fustes compensadas con basas o en el uso de estas como capiteles y viceversa. Es decir, las piezas antiguas asumen el papel de material constructivo.

Es precisamente en este segundo periodo en el que centraremos nuestra atención para la Península Ibérica, que, a diferencia de Italia, apenas cuenta con trabajos sobre la reutilización. A mediados de los años setenta, Deichmann ${ }^{12}$ llegó a afirmar que no se conservaba en España ningún ejemplo tardoantiguo significativo de edificio con material expoliado, ni sacro ni profano. Décadas después, el incremento de los datos arqueológicos en la Península ha permitido ampliar notablemente el catálogo de conjuntos que recurren a la reutilización y modificar así el panorama arquitectónico de estos periodos ${ }^{13}$. Su análisis evidencia, en nuestra opinión, que la reutilización forma parte de la tecnología constructiva ${ }^{14}$, que por ello cuenta con sus tiempos y una planificación concreta, que requiere de sus propios especialistas, necesidades y gastos que deben ser contemplados y asumidos en el proyecto constructivo, el cual se verá determinado por una economía de esfuerzos. Las intenciones ideológicas de los grandes programas constructivos de Constantino en Roma, Teodorico en Rávena o Carlomagno en Aquisgrán son acciones de calado político emprendidas por estos gobernadores. Aunque es cierto que algunas monarquías locales y crecientes noblezas altomedievales pudieron imitar los modos de aquellos, resulta muy complicado extrapolar a todos los proyectos edilicios tardoantiguos y altomedievales las mismas consideraciones. Eso significaría otorgar los mismos valores a todos los materiales reutilizados, incluso a todos los edificios donde se trabaja con expolio. Debe tratarse en su propia dimensión la reutilización en otras regiones, como pretendemos demostrar en las iglesias hispánicas.

\section{LA REUTILIZACIÓN COMO PARTE DE LA TECNOLOGÍA CONSTRUCTIVA}

La reutilización puede entenderse como respuesta universal a las limitaciones de la tecnología o los recursos ${ }^{15}$. Sin embargo, su práctica es requerida por comitentes de mayor o menor rango, traspasando así los diferentes niveles sociales, y se constata tanto en obras de patrocinio imperial, sea en época romana o carolingia, como de me-

\footnotetext{
12 F. W. DEICHMANN, op. cit., 1975, p. 32, basándose en la obra de P. DE PALOL I SALELLAS, Arqueología cristiana de la España romana, Madrid, 1967.

13 Algunas notas sobre las iglesias hispánicas en M. GREENHALGH, Marble Past, Monumental Present. Building with Antiquities in the Mediaeval Mediterranean, Leiden-Boston, 2009, pp. 505-510.

14 Como propone para época romana S. BARKER, "Roman Builders - Pillagers or Salvagers? The Economics of Deconstruction and Reuse", S. CAMPOREALE, H. DESSALES y A. PIZZO (eds.), Arqueología de la Construcción II. Los procesos constructivos en el mundo romano: Italia y provincias orientales, Anejos de AEspA 57, Madrid-Mérida, 2010, pp. 127-140.

15 D. KINNEY, "The concept of Spolia", C. RUDOLPH (ed.), Companion to Medieval Art: Romanesque and Gothic in Northern Europe, Williston, 2006, pp. 233-252 (p. 233).
} 
cenazgo menor, donde se incluyen abades, obispos o iniciativas privadas ${ }^{16}$. La reutilización se muestra así como una práctica cultural distintiva que debe independizarse a la hora de ser analizada en sus propios términos ${ }^{17}$, no como una mera supervivencia de época clásica. Su habitual y extendida presencia la convierte en un aspecto fundamental de la tecnología y en un recurso a tener en cuenta, pues debemos pensar que, al igual que el material extraído en cantera, formaba parte de la génesis y desarrollo del proyecto constructivo. No era un elemento sorpresivo, sino integrante.

La reutilización comprende una serie de actividades encadenadas que comienza en la selección del material a reutilizar, su extracción, bien de un edificio aún en pie o ya arruinado, su transporte, su reelaboración, en caso necesario, y su puesta final en obra. Esta cadena de actividades, aun muy desconocida para el periodo que pretendemos estudiar ${ }^{18}$, apenas se diferencia de la que se pone en marcha cuando el material proviene de cantera, pues todos los pasos citados son necesarios en ambos casos para llevar a cabo el proyecto constructivo, residiendo la diferencia principal entre ambos en la fase de extracción del material. Sí debemos puntualizar sin embargo que los protagonistas son distintos: si hay canteras es porque hay canteros capaces de hacerlas funcionar y, viceversa, la ausencia de canteros conlleva la desaparición de las canteras. En otras palabras, para que se abran canteras no solo debe haber construcciones en marcha, sino mano especializada ${ }^{19}$. Analicemos esa cadena.

Extracción del material.- Si el trabajo en cantera natural implica fundamentalmente extraer el material ${ }^{20}$, el trabajo en un edificio-cantera debe combinar la demolición con la labor de recuperación o extracción de los materiales destinados a un nuevo uso constructivo $^{21}$. La demolición de un edificio aún en pie y/o en reciente funcionamiento podría llegar a requerir unos recursos similares a los de la construcción. El empleo de andamios para acceder a los materiales o tal vez de montículos de arena sobre los que arrojar y depositar el material durante la labor de desmonte, así como la presen-

16 J. B. WARD-PERKINS, "Quarries and Stoneworking in the Early Middle Ages: the Heritage of the Ancient World", XVIII Settimane di Studio del Centro Italiano di Studi sull'alto medioevo: Artigianato e Tecnica nella società dell'alto medioevo occidentale, Spoleto 1970, II, Spoleto, 1971, pp. 525-544 (p. 541 ).

17 Como ya identificó A. ESCH, "Zur Wiederverwendung antiker Baustücke und Skulpturen im mittelalterlichen Italien", Archiv für Kulturgeschichte, 51 (1969), pp. 1-64.

18 Algunas notas en L. SÁNCHEZ ZUFIAURRE, Erdi Aroko Eraikuntza Teknikak-Técnicas Constructivas Medievales, Vitoria-Gasteiz, 2007.

19 M. Á. UTRERO, "A finales del siglo IX e inicios del X. Entre Asturianos y Mozárabes", L. CABALlERO, P. MATEOS y C. GARCIÁ DE CASTRO (eds.), Asturias entre visigodos y mozárabes, VI Visigodos y Omeyas, Madrid 2010, Anejos de AEspA LXIII, Madrid, 2012, pp. 125-145.

20 El estudio de las canteras catalanas (A. GUTIÉRREZ, Roman Quarries in the Northeast of Hispania (Modern Catalonia), Tarragona, 2009) parece demostrar que una parte de las canteras hispano-romanas se abrieron para desarrollar ambiciosos programas urbanísticos, muchos ligados a la fundación de ciudades, mientras que otras canteras menores, con un volumen reducido de material, satisficieron proyectos concretos y geográficamente muy cercanos. Salvo la fundación de Recópolis (Guadalajara), estos programas desaparecen en la Antigüedad Tardía, argumentándose aún más el final del sistema de canteras naturales en los siglos IV-V. Los proyectos tardoantiguos y altomedievales se nutrirían en parte con excedentes de aquel proceso industrial, sin tener que acudir al sistema de extracción geológica.

21 S. BARKER, op. cit., 2010, p. 127, lo denomina “deconstrucción”. 
cia de canteros especializados en este trabajo ${ }^{22}$, que garantizasen que las piezas se recuperasen con suficiente solvencia y calidad para ser utilizadas de nuevo, serían requisitos habituales de este proceso. Estos factores hacen pensar hasta qué punto no se trataba en realidad de una labor necesariamente organizada ${ }^{23}$. Especial cuidado debía tenerse, por ejemplo, en el desmonte de piezas singulares, como las que componen las columnas, o menores ${ }^{24}$, lo que hace imprescindible la presencia de trabajadores (canteros y transportistas) especializados en la labor de desmonte.

Esta primera fase cambia si el edificio-cantera se encuentra ya arruinado o demolido y, por ello, su material menos trabado y más accesible. Parece que la distancia temporal entre el final del imperio romano y el altomedievo pudo suponer no solo la existencia de un número menor de piezas disponibles, como defienden algunos autores ${ }^{25}$, sino que el estado de conservación de los monumentos romanos se encontrase en un estadio de avanzada ruina, lo que significa, como hemos indicado previamente, un mejor acceso y obtención de las piezas a expoliar al prescindir o minimizar tanto en coste como en duración la fase de demolición. Sin embargo, no sería tampoco sencillo cuando el edificio arruinado se encontrase enterrado o semienterrado, condición que debió implicar más de una vez excavaciones del lugar para la extracción del material ${ }^{26}$. Aunque este hecho es difícilmente medible, pues deberíamos conocer arqueológicamente las etapas de los expolios de los yacimientos abastecedores, de nuevo debemos pensar en la presencia de "expoliadores" experimentados que conociesen el terreno y sus posibilidades ${ }^{27}$. Por lo tanto, teniendo en cuenta el esfuerzo que podía implicar la extracción de materiales de construcciones arruinadas, el ahorro

22 P. ROCKWELL, Lavorare la pietra. Manuale per l'archeologo, lo storico dell'arte e il restauratore, Roma, 1992 (1 ${ }^{\text {a }}$ ed., 1989), p. 202; y S. BARKER, op. cit., 2010, p. 128.

23 R. SANTANGELI, "Public and Private Building Activity in Late Antique Rome", L. LAVAN, E. ZANINI y A. SARANTIS (eds)., Technology in Transition, A.D. 300-650, Late Antique Archaeology 4, Leiden-Boston, 2007, pp. 435-449, lo explica así para la Roma tardoantigua (pp. 442-443).

24 El esmero con el que sacaban las columnillas de mármol se aprecia en las huellas de extracción de las aras y los soportes de altares, como en Casa Herrera (Mérida), donde el diámetro de la fosa de expolio duplica al de las piezas, cavándose alrededor con suficiente profundidad para extraerlas enteras. Los restos desmochados de las basas de las columnitas, como los del pie suroeste del altar de Casa Herrera y el noreste de Santa Lucía del Trampal (Cáceres), demuestran que algunas veces la pieza se rompía en la zona inferior, posiblemente por el fuerte agarre del mortero hidráulico de unión con el pavimento.

25 A. ESCH, "Reimpiego", Enciclopedia dell'Arte Medievale, Roma, vol. IX, 1998, pp. 876-883 (p. 877 ).

26 D. KINNEY, op. cit., 2006, p. 234, recoge la cita sobre las excavaciones de la ciudad romana de Verulamium (St Albans, Reino Unido) por parte del abad Eadmar para la construcción de la abadía de St Albans en el siglo X.

27 Datos al respecto se constatan en la curia del foro romano de Segóbriga (Cuenca), cuyo abandono tiene lugar en los siglos IV-V (A. ÁLVAREZ, R. CEBRIÁN e I. RODÀ, "El mármol de Almadén de la Plata y los marmora del foro de Segóbriga", T. NOGALES y J. BELTRÁN (eds.), Marmora Hispana: explotación y uso de materiales pétreos en la Hispania Romana, Roma, 2008, pp. 101-120, p. 113 y fig. 3). Aquí el expolio abrió grandes zanjas que llegaban hasta la primera hilada de cimentación del edificio. Algunos sillares sueltos y descolocados de la segunda hilada parecen indicar que el expolio cesó una vez se contaba con el material necesario para la nueva obra. La puesta en marcha de un proyecto constructivo concreto (posiblemente tardoantiguo, de acuerdo al material de colmatación de las zanjas de inicios del siglo V) habría provocado la búsqueda de material. No hay datos para relacionar este saqueo con la iglesia extramuros, en la que los materiales reutilizados son más tardíos (M‥ Á. UTRERO, Basílica de Segóbriga (Saelices, Cuenca). Lectura de paramentos, Informe manuscrito, IH-CCHS, Madrid, 2007). 
real que supondría el empleo de material expoliado respecto al de la extracción en cantera requiere ser mesurado con propiedad.

Una tercera posibilidad sobre el origen de material, apenas contemplada hasta fechas recientes por la investigación, es el uso de piezas que en realidad no provienen de construcciones previas. Estos elementos, una vez fabricados, no habrían sido utilizados, por lo que habrían permanecido en almacenes, siendo empleados por primera vez en las obras en las que se han considerado como reutilizados ${ }^{28}$. El análisis arqueológico de este proceso se antoja complicado, pues su constatación pasa por identificar huellas de "desuso" o de almacenamiento en los materiales, y afecta principalmente a las columnas de mármol, cuya casi automática aceptación como material reutilizado se basa en el cese de la explotación de sus canteras en época tardoantigua y altomedieval ${ }^{29}$.

Transporte del material.- Respecto a la fase de transporte del material desde la cantera al solar de construcción, al igual que la fase final de puesta en obra, entendemos que tanto su duración como su coste son similares tanto si el material es nuevo como reutilizado. A pesar de que el estudio de las canteras altomedievales en la Península está aún por hacer, siendo los ejemplos mejor estudiados los pertenecientes al prerrománico asturiano ${ }^{30}$, se acepta como habitual la proximidad de fuente de extracción y lugar de construcción. Si este hecho parece un factor constante, debemos pensar que la búsqueda de material para reutilizar como elemento constructivo no debía alejarse en exceso, evidenciando la existencia de una premisa económica en la búsqueda de material por delante de otros factores como el simbólico-ideológico o el estilístico-iconográfico. De hecho, cuando se constata la reutilización, la investigación ha tendido a identificar como cantera un yacimiento romano cercano a la iglesia, como reflejan las relaciones establecidas entre la ciudad de Bobadela y São Pedro de Lourosa (Oliveira do Hospital) ${ }^{31}$, la villa de Boides y San Salvador de Valdediós (As-

28 Algunos ejemplos citados por P. PENSABENE, "Reimpiego e depositi di marmi a Roma e a Ostia", S. ENSOLI y E. LA ROCCA (eds.), Aurea Roma. Dalla città pagana alla città cristiana, Roma, 2000, pp. 314350; R. COATES-STEPHENS, "Attitudes to spolia in Some Late Antique Texts", L. LAVAN y W. BOWDEN (eds.), Theory and Practice in Late Antique Archaeology, Leiden, 2003, pp. 341-358; D. KINNEY, "Bearers of Meaning", Jahrbuch für Antike und Christentum, 50 (2007), pp. 139-153; y M. GREENHALGH, op. cit., 2009, pp. 111-124.

29 J. B. WARD-PERKINS, op. cit., 1971.

30 Referencias en L. CABALLERO y Ma . Á. UTRERO, "Una aproximación a las técnicas constructivas de la Alta Edad Media en la Península Ibérica. Entre visigodos y omeyas", Arqueología de la Arquitectura, 4 (2005), pp. 169-192 (p. 175); y Má. Á. UTRERO, Iglesias tardoantiguas y altomedievales en la Península Ibérica. Análisis arqueológico y sistemas de abovedamiento, Anejos de AEspA 40, Madrid, 2006, p. 177. Análisis recientes efectuados en algunos edificios ovetenses (F. J. MATEOS, L. VALDEÓN y A. ROJO, "Piedras de construcción de la fuente prerrománica de Foncalada: tipos y origen", Trabajos de Geología, 24 (2004), pp. 107-118; y B. GONZÁLEZ, C. MARCOS y E. MENÉNDEZ, "Hydrogeological and Minerological Analysis of the Pre-Romanesque Monument of Santa María del Naranco, Asturias, Spain”, Geoarchaeology: An International Journal, 25/4 (2010), pp. 497-513) confirman la proximidad de la cantera.

31 L. FERNANDES, "A ordem toscana na Lusitânia ocidental: problemática e caracterização do seu emprego: a propósito das peças reutilizadas da Igreja de S. Pedro de Lourosa (Coimbra)", Revista Portuguesa de Arqueologia, 11/2 (2008), pp. 231-270, acepta la analogía de las piezas reutilizadas de Lourosa con las conservadas en Bobadela (pp. 259-260), pero considera sin embargo que no proceden de allí y que reflejan la existencia de un centro religioso romano en la propia Lourosa, hipótesis por probar. 
turias), la ciudad de Lancia y San Miguel de Escalada (León) o el yacimiento de Las Torrecillas y Santa Lucía del Trampal (Cáceres), entre otras, relaciones probables, aunque casi todas ellas aún por probar ${ }^{32}$. Un ejemplo destacado por la dimensión de los elementos reutilizados es la iglesia de Santa María de los Arcos de Tricio (La Rioja), cuyos muros se alzan con material romano (arquitrabes, pilastras, inscripciones, sillares), destacando notablemente las columnas de las arquerías del aula. De modo inusual, se reutilizan grandes tambores acanalados, dispuestos irregularmente, en una forma que no duda incluso en sacrificar el uso de capiteles (también reutilizados, pero no presentes en todos los soportes), otorgando así una imagen desproporcionada al interior del aula. El esfuerzo de transporte de material, a pesar de su gran tamaño, debió ser mínimo, al ser la cantera la propia ciudad romana de Tritium Magallum, cuyo núcleo no puede situarse más allá de $500 \mathrm{~m}$ de la basílica. La dimensión de los tambores (y de algunos sillares, con longitudes de 1,50 m) refleja el expolio de un gran edificio ${ }^{33}$, planteando hasta qué punto las columnas monolíticas de mármol que observamos en otras iglesias no procederían de ámbitos domésticos.

Sin embargo, la decisión de conseguir ciertos materiales singulares, bien por su material, significado o forma, puede romper el principio de proximidad, conllevando un mayor gasto debido al incremento del coste del transporte de materiales de procedencia lejana. En este caso el deseo de obtener una pieza particular se impone a la condición de proximidad geográfica. Así sucedería con el ara de altar del grupo lusitano-toledano hallado en Wamba (Valladolid), producido en mármol y de forma estandarizada por los talleres de Mérida y Beja (Portugal) a partir del tercer cuarto del siglo VI, pero ausente en la meseta norte. Lo mismo sucede con el capitel bizantino datado en el siglo V que se encontraba en la iglesia de Santa María de Wamba. La restante escultura decorativa conocida en Wamba es de caliza y se data en el siglo X, lo que enfatiza todavía más su excepcionalidad. Carecemos de datos sobre el transporte de este tipo de materiales, siendo nuestras únicas referencias las de época romana, de las cuales se concluye obviamente un importante incremento en el precio final del material foráneo ${ }^{34}$.

32 Con la excepción del Trampal, donde los indicios de la epigrafía reutilizada hacen muy probable que el yacimiento de Las Torrecillas sea el origen de los materiales: L. CABALLERO y F. SÁEZ, La iglesia mozárabe de Santa Lucía del Trampal, Alcuéscar (Cáceres). Arqueología y Arquitectura, Mérida, 1999, p. 120.

33 M. P. SÁENZ PRECIADO, "Tricio (La Rioja). Últimas actuaciones realizadas en la Ermita de Nuestra Señora de los Arcos", Estrato, 10 (1999), pp. 11-19, considera que el material provendría del templo, pero faltan datos para confirmarlo. L. CABALLERO, F. ARCE y M. Á. UTRERO, "Santa María de los Arcos de Tricio (La Rioja), Santa Coloma (La Rioja) y La Asunción de San Vicente del Valle (Burgos). Tres miembros de una familia arquitectónica", Arqueología de la Arquitectura, 2 (2003), pp. 81-85, documentan una primera iglesia con ábside rectangular y nave única, sustituida después por un aula de tres naves. Ambas fases aprovechan material romano, pero lo hacen de distinta manera: reelaboración de una sillería bien cortada y aparejada en la primera, de menor tamaño e irregular disposición en la segunda. Por lo tanto, aunque la fuente de material es la misma, no lo son los canteros.

34 Muy alto era el coste del transporte terrestre del mármol, lo que le convertía en un producto exclusivo al alcance de las élites urbanas. P. SILLIÈRES, Les voies de communication de l'Hispanie Méridionale, París, 1990, pp. 761-762, calcula un coste del 133\% del valor del mármol para su transporte terrestre en una distancia de cien millas. M. GREENHALGH, op. cit., 2009, pp. 131-136, distintos cálculos. 
El coste del transporte se elimina o minimiza en los casos de construcciones levantadas en los mismos enclaves romanos, como pueden ser los ejemplos de las basílicas urbanas tardoantiguas (gran parte de las basílicas de Roma; en la Península Ibérica, Santa Eulalia de Mérida o las basílicas tarraconenses, por ejemplo) ${ }^{35}$, o en construcciones que en fases ulteriores de reconstrucción reutilizan los materiales de fases previas, como ejemplifican las iglesias burgalesas de La Asunción de San Vicente del Valle (fases II y III) ${ }^{36}$ y San Pedro de Arlanza (fase II) ${ }^{37}$. Esta reutilización forma parte en realidad de un proceso de reforma que se vale del material disponible en la propia obra, el cual requiere por tanto el único esfuerzo del retalle para cumplir su nueva función.

Al valorar procedencia, coste y uso del material reutilizado, debemos observar con precaución la presencia de materiales de distinto origen y calidad en un mismo edificio. El uso de un mármol costoso y excepcional puede ser un indicio a favor de su búsqueda intencionada, lo que le diferencia de otros elementos reutilizados. Sin embargo, ambos pueden tener un mismo origen. Los análisis de los edificios romanos, principalmente de carácter público, demuestran el empleo simultáneo de varios tipos de mármoles y calizas ${ }^{38}$. El verdadero coste excepcional de su transporte se habría dado en su primer uso, mientras que en el tiempo en que fue expoliado habría que aplicar los mismos parámetros de costes que al resto del material de acarreo. Esto mismo vale para la presencia de distintos mármoles hispanos, que en origen también pudieron formar parte de un mismo proyecto arquitectónico. De todo ello se habrían beneficiado los constructores de iglesias cercanas a los antiguos núcleos urbanos ${ }^{39}$.

Reelaboración del material en obra.- Respecto a la fase de reelaboración del material, de nuevo se abre otro abanico de posibilidades. La reelaboración puede ser parcial o completa. Piezas singulares como los capiteles, fustes y basas suelen utilizarse para un mismo fin, componer una columna, pero aun así requerirían un proceso complejo de acoplamiento (elevaciones, recortes, retallados o añadido de elementos para completar el soporte) con el fin de obtener una altura uniforme y adaptar este material exógeno al nuevo proyecto de obra. Tanto la reutilización de columnas como de sillería en los paramentos implica un trabajo de retalle que exige la presencia de mano

35 Una síntesis de la reutilización en las ciudades hispanas tardoantiguas: J. M. GURT y P. DIARTE, "Spolia et Hispania: alcuni esempi peninsulari”, Hortus Artium Medievalium, 17 (2011), pp. 7-22.

36 Según F. ARCE, "La iglesia altomedieval de la Asunción en San Vicente del Valle (Burgos): historiografía, estratigrafía e interpretación", Arqueología de la Arquitectura, 7 (2010), pp. 67-103.

37 Según L. CABALlERO, P. LATORRE y P. MATESANZ, "La iglesia prerrománica de San Pedro el Viejo (Hortigüela, Burgos)", Numantia, 5 (1994), pp. 139-165.

38 En los edificios forales de Segóbriga (Cuenca) aparecen, junto a los mármoles y calizas hispanos, mármoles importados de otras provincias (ẢLVAREZ et alii, op. cit., 2008, pp. 108-109). Aunque su volumen es bastante menor $-27 \%$ del total-, este es suficiente para plantear la posibilidad de encontrar estos materiales en un lote de expolio y generar la duda sobre el valor real de su uso.

39 En la basílica de Segóbriga se reutilizó un fragmento de capitel de lesena del siglo I d.C., fabricado en mármol de Almadén de la Plata (Sevilla), uno de los materiales usados en el foro romano de la ciudad (Ibídem, pp. 112-113, fig. 9). No existió por tanto un transporte desde Sevilla, sino una recogida de material de algún edificio abandonado y situado a menos de $1 \mathrm{~km}$. Sin embargo, en el caso citado del ara de altar de Wamba es su pertenencia a un taller especializado en su producción y no tanto su material lo que confirma la particularidad de su reempleo. 
especializada (conocimientos de cantería). Los sillares de mayor tamaño tendrían un mayor valor, pues tenían la posibilidad de una mayor adaptación ${ }^{40}$, pero tanto estos como los de menor tamaño requerían igualmente una labor de talla (y de limpieza de las superficies de morteros antiguos) que facilitase su nuevo emplazamiento.

Una reelaboración parcial se da también en la mayoría de piezas que fueron reutilizadas como mobiliario litúrgico, sobre todo en altares y elementos para canceles tales como carrileras, donde a veces se emplean estelas romanas volcadas (El Gatillo y Santa Lucía del Trampal, ambas en Cáceres). Para realizar altares se aprovecharon antiguas aras, cipos y otros materiales romanos con formas prismáticas o cilíndricas. La principal modificación realizada a la pieza previa es la apertura en su cara superior de un hueco rectangular con escalón para servir como loculus de reliquias. Si el elemento reutilizado es un ara pagana, se aprovecha el focus circular, dándole la forma cuadrangular y mayor profundidad. En estos casos además se alisa la superficie, para lo que muchas veces es necesario cortar y picar el coronamiento de las piezas. También se puede preparar la parte inferior con el fin de facilitar su asentamiento, como en las aras de Idanha-a-Velha (Portugal) y de Gines (Sevilla). La transformación de aras paganas en aras cristianas fue una práctica muy extendida en la Península, con más de un centenar de ejemplares documentados ${ }^{41}$, de los que sin embargo solo podemos datar con certeza una decena, a partir del siglo VII y durante toda la Alta Edad Media, gracias a la presencia de epígrafes en ellos.

La reelaboración completa del mobiliario litúrgico se produce cuando hay una importante concentración de expolio en núcleos que tuvieron talleres de escultura en época romana y que siguieron activos o se reactivaron en periodos de gran dinamismo. Estos son por ejemplo los talleres lusitanos de Beja y Mérida, los cuales se benefician de su proximidad geográfica a las canteras de mármol de Borba-Estremoz y Trigaches y de su condición anterior de capitales romanas. Los altares están aquí totalmente reelaborados. De la pieza antigua solo conocemos su forma prismática, siendo organización, talla y composición iconográfica nuevas. Posiblemente la producción de este tipo de altar surgió en el tercer cuarto del siglo VI y se mantuvo, con evoluciones iconográficas y en la técnica de labra, hasta finales del siglo VIII e inicios del IX.

$\mathrm{Al}$ igual que sucede con los altares, cuando un sillar empleado en la nueva obra ha sido notablemente alterado en su forma, la reutilización puede pasar desapercibida a los ojos del observador, ya que las nuevas huellas pueden llegar a borrar las del uso previo. Sin embargo, la presencia de aristas escantilladas, de hiladas con orientaciones ondulantes, de tallas y retalles en las superficies de los sillares, de huecos dejados por las tenazas de elevación en posición descentrada y visible o diferentes dimensiones entre ladrillos de una misma etapa son, entre otros, claros indicios de reutilización, aunque, como hemos advertido, no siempre conservados y/o reconoci-

40 P. ROCKWELL, op. cit., 1992, p. 203.

41 L. CABALLERO y J. C. SÁNCHEZ, "Reutilizaciones de material romano en edificios de culto cristiano", Antigüedad y Cristianismo, VII (1990), pp. 431-485 e I. SASTRE DE DIEGO, El altar en la arquitectura cristiana hispánica (siglos V-X). Estudio arqueológico, Tesis doctoral, Universidad Autónoma de Madrid, 2009. 
bles en el material. En cuanto a las piezas cilíndricas, columnas y columnitas, que han sido reutilizadas como estípites de altar, en ocasiones queda la marca del retalle de las caras, ya que el volumen se ha reducido para poder sacar de la misma pieza las partes de la basa y el capitel en forma cúbica. Como resultado de esta operación, la zona que queda como nuevo fuste es irregular, perdiéndose la perfección del círculo, como en el de la basílica de Alconétar (Cáceres) y en las columnitas de la llamada "basílica del km 359" en las cercanías de Mérida. En la iglesia de San Pedro de Mérida optaron por una solución distinta: reutilizaron basas romanas exentas sobre las que asentarían directamente los soportes del altar, evitando así retallar fustes ${ }^{42}$.

Puesta en obra del material.- Finalmente, la puesta en obra de los materiales no tiene nada que ver con la procedencia de estos. La combinación de piezas nuevas y reutilizadas demandará la integración correcta de ambas, proceso que depende de un proyecto constructivo que lo contemple desde su génesis, pero no supondrá un coste añadido a nivel de infraestructura ni de mano de obra. A este respecto, la identificación de los soportes como unidad modular de las construcciones asturianas ${ }^{43}$, como también parece constatarse en otros entornos ${ }^{44}$, y el habitual carácter reutilizado de estos supone un condicionante a tener en cuenta en la concepción de la volumetría final de las construcciones. Tal vez ello explique en parte por qué la arquitectura prerrománica asturiana relega las columnas reutilizadas a posiciones secundarias (constructivamente hablando), normalmente sujetando los arcos de embocadura de los ábsides (plintos de arenisca, basas, fustes y capiteles ${ }^{45}$ del arco de embocadura del ábside central de Santo Adriano de Tuñón, ábsides laterales de San Salvador de Valdediós, entre otros) o los arcos ciegos decorativos de los muros de los mismos (pilastras y fustes marmóreos, basas y capiteles en la cabecera de San Julián de los Prados $\left.^{46}\right)$, mientras que las arquerías de las aulas, que habrían necesitado una mayor cantidad de columnas, se sustentan sobre pilares de obra o de piezas monolíticas de nueva ejecución. La presencia exclusiva de columnas de mármol reutilizadas en las arquerías de las basílicas de San Miguel de Escalada (León) o San Cebrián de Mazote (Valladolid), sobre las cuales volveremos más adelante, no deja por ello de llamar la atención al respecto.

42 Ibídem, Los primeros edificios cristianos de Extremadura y sus elementos litúrgicos. Caelum in Terrae, Serie Ataecina $\mathrm{n}^{\circ}$ 5, Mérida, 2010.

43 L. ARIAS PÁRAMO, Geometría y proporción en la Arquitectura Prerrománica Asturiana, Anejos de AEspA 49, Madrid, 2008.

44 R. OUSTERHOUT, Master Builders of Byzantium, Princeton, 1999, pp. 145-146, para Bizancio.

45 Con propuestas que datan los capiteles entre finales del siglo VI y VII (L. CABALLERO y R. MARTÍN, "Santo Adriano de Tuñón y su entramado de madera", L. CABALLERO et alii, Las iglesias asturianas de Pravia y Tuñón. Arqueología de la Arquitectura, Anejos de AEspA 44, Madrid, 2010, pp. 91-154, p. 103).

46 S. NOACK-HALEY, "Westgotenzeitliche Kapitelle im Duero-Gebiet und in Asturien", Madrider Mitteilungen, 27 (1986), pp. 389-409, opina que estos capiteles procederían del monasterio visigodo de Santa María de Wamba (Valladolid), influyendo estas piezas expoliadas en el desarrollo de la plástica de los capiteles asturianos junto a los cuales se reutilizan. Tanto la existencia de un monasterio visigodo como el expolio de sus piezas es, a día de hoy, difícil de confirmar. 


\section{ALGUNOS EJEMPLOS}

Como ya hemos advertido, son numerosos los ejemplos arquitectónicos que reutilizan materiales constructivos y decorativos en su obra. Dentro de la gran lista de conjuntos que podríamos traer a colación, algunos ya mencionados, nos fijaremos en aquellos que ofrecen una serie significativa de datos. Estos conjuntos podemos ordenarlos en dos categorías que responden a circunstancias muy distintas. La primera la forman aquellos edificios que reutilizan materiales propios, realizados para su obra pero que, debido a un cambio de proyecto, son empleados para un fin distinto al que fueron concebidos. Este cambio de idea fuerza y, al mismo tiempo, se beneficia del empleo de piezas que estaban destinadas a otra función en el mismo edificio.

Así ocurre en la iglesia de San Pedro de la Nave (Zamora), donde se constata el empleo de al menos siete inscripciones romanas de granito en los muros y pavimentos del edificio $^{47}$. Los fustes de mármol de las seis columnas de su interior así como algunas otras piezas (algunas ejecutadas en granito) son también reutilizados. El edificio presenta además la particularidad de haber sido decorado por dos "manos" o talleres que labran modelos distintos. Es el denominado primer maestro el que no duda en sacrificar algunas de las piezas elaboradas por él mismo insertándolas como sillares constructivos, cuya decoración queda por ello oculta (total o parcialmente) ${ }^{48}$. Parece ser que el reajuste del proyecto iconográfico obligó a los canteros a prescindir de estas piezas, todas ellas talladas de modo independiente (como evidencian los marcos perimetrales de las caras de los sillares) y, pasaron así a desempeñar una función constructiva dentro del mismo proyecto, perdiendo su valor como elementos decorados.

El hecho de que materiales diseñados para ser expuestos como elementos decorativos se conviertan en el mismo proyecto en piezas constructivas no hace más que evidenciar un esquema constructivo que se rige por una economía de esfuerzo y de material, aprovechando los elementos disponibles. La reutilización de piezas romanas, cuyas inscripciones quedaban ocultas, viene a confirmar la misma idea ${ }^{49}$.

Algo similar al grupo escultórico de La Nave se constata en la iglesia de San Miguel de Lillo (Oviedo). Su análisis arqueológico ${ }^{50}$ documenta cómo el cambio del proyecto constructivo en marcha al que se somete el edificio para dotarle de una tribu-

47 L. CABALlero y F. ARCE, "Arqueología de la Arquitectura de la iglesia de La Nave”, L. CABALLERO (coord.), La iglesia de San Pedro de La Nave, Zamora, 2004, pp. 115-197 (pp. 124-136).

48 De hecho, algunas solo pudieron ser documentadas durante las labores de desmonte y traslado de la iglesia, tuteladas por M. Gómez Moreno (Ibídem, pp. 153-155).

49 Aunque el altar de La Nave se realizó con materiales nuevos, es llamativo que todos sus elementos (pilastrillas del ara y de los cuatro soportes angulares) tengan una forma prismática, lo que contrasta con la tipología tradicional de este altar, que usaba columnitas para los estípites, y con la propia iconografía presente en la iglesia, pues es la forma tradicional la que aparece representada en el capitel del sacrificio de Isaac. La sustitución de columnitas por pilastrillas pudo deberse a la falta de material reutilizable para ese fin y a la mayor facilidad y habilidad que el escultor poseía para labrar un bloque prismático.

50 L. CABALLERO et alii, La iglesia de San Miguel de Lillo (Asturias). Lectura de paramentos. 2006, Oviedo, 2008; L. CABALLERO, "Observaciones arqueológicas sobre producción arquitectónica y decorativa de las iglesias de S. Miguel de Lillo y Santianes de Pravia”, L. CABALLERO, P. MATEOS y C. GARCÍA DE CASTRO (eds.), Asturias entre visigodos y mozárabes, VI Visigodos y Omeyas, Madrid 2010, Anejos de AEspA 63, Madrid, 2012, pp. 89-124. 
na occidental supone una adaptación de los espacios y de los materiales. Un segundo taller de escultura realiza las piezas que pertenecen a la citada tribuna y es responsable de la reutilización en ella de algunas piezas (basas cortadas, capiteles retallados, impostas de arcos y de bóvedas) del primer taller, diseñadas para otra ubicación o inacabadas. Si este taller emplea preferentemente piedra arenisca, el segundo utiliza prioritariamente caliza blanca y talla molduras planas y escultura plana y a bisel con un repertorio diferente. Al primer taller pertenecerían las conocidas placas con las escenas de circo de las jambas $^{51}$ que, contextualizadas en la zona de reforma del edificio, bajo la tribuna, puede que estuvieran destinadas originalmente a otro emplazamiento o vano.

La iglesia no es fruto de dos proyectos, sino de uno único modificado en marcha, proceso que permitió la puesta en obra de materiales, como las jambas citadas, que aún no habían sido usados, pero que sin embargo estaban finalizados. Como en La Nave, las piezas se reconvierten, dinamizando así la ejecución del proyecto al aprovechar el material disponible. En términos técnicos, podemos decir que estas piezas fueron más bien recolocadas que reutilizadas, requiriendo apenas reelaboración para su nuevo uso.

Dentro de la segunda categoría, la de edificios que reutilizan materiales expoliados de construcciones previas, entrarían gran parte de los conjuntos conocidos. Unos edificios reutilizan tanto sillería como piezas singulares. Podemos mencionar aquí Santa Comba de Bande (Orense), donde se busca intencionadamente mármol para su altar, en una región, el noroeste peninsular, caracterizada por el uso y reutilización del granito, material que se emplea exclusivamente en sus muros. Además del altar, se reutiliza una pareja de capiteles en el arco de embocadura del ábside. También Quintanilla de las Viñas (Burgos) alza sus muros con sillares reutilizados de origen romano, en los cuales también talla sus decoraciones (impostas), y reemplea los fustes de las columnas. Como en La Nave, en Quintanilla los soportes del altar pasan de ser cilíndricos a prismáticos, pero aquí sí retallan piezas romanas de mármol blanco y elaboran una iconografía novedosa, que aunque a priori parece imitar a la antigua de los talleres lusitanos y de Toledo, presenta notables diferencias ${ }^{52}$. Esta reelaboración de las piezas requiere la contratación de un escultor especializado con conocimientos y destreza en programas decorativos actualizados. En San Juan de Baños (Palencia), aunque no se puede asegurar la reutilización de la sillería, el taller decorativo sí que usa escultura expoliada, a la vez que copia sus modelos y los alterna con otros distintos.

Un buen ejemplo lo constituye Santa Lucía del Trampal (Cáceres) ${ }^{53}$. En esta iglesia se reutilizan sillares de granito, aras y laudas funerarias romanas, procedentes tal vez de un mismo lugar (Las Torrecillas, a $9 \mathrm{~km}$ ). Con este material, los canteros fabrican cadenas de esquina, marcos de vanos, verdugos de muros y bóvedas. Los albañiles obtenían

51 Sobre su simbología y origen iconográfico: L. ARIAS, "Recurso a los spolia como instrumento de prestigio y poder en el arte prerrománico asturiano (siglos VIII-X)”, TH. G. SCHATTNER y F. VALDÉS (eds.), Spolien im Umkreis der Macht - Spolia en el entorno del poder, Toledo 2006, Iberia Archaeologica 12, Mainz am Rhein, 2009, pp. 199-228 (pp. 219-222).

52 I. SASTRE DE DIEGO, op. cit., 2009.

53 L. CABALLERO y F. SÁEZ LARA, op. cit., 1999; y L. CABALLERO y M"a Á. UTRERO, "Cómo funcionaban los talleres constructivos en la Alta Edad Media hispánica”, Homenaje al profesor José Ángel García de Cortazar, Santander, 2011 (en prensa). Mundos medievales: espacios, sociedades y poder. Homenaje al profesor José Ángel García de Cortazar, Univ. de Cantabria, Santander, 2013, 427-440. 
la mampostería del terreno inmediato, pero también reutilizaban ladrillos y tégulas, los cuales podían provenir del mismo expolio. Para labrar las esculturas se emplea mármol romano, siendo el artífice un taller situado probablemente en Mérida, el cual también sirve a una reforma de la basílica de Santa Eulalia, a otros edificios de la ciudad ${ }^{54}$ y a los alrededores de Montánchez. Para sostener la mensa o como ara del altar del ábside norte se aprovechó un fuste liso de mármol blanco, pero para encajarlo en el pavimento se tuvo que tallar un basamento en granito donde se insertó el fuste. Estelas funerarias romanas son, por dimensión y forma (rectas y planas), fácilmente transformadas a pie de obra en carrileras de cancel.

Otros conjuntos reutilizan únicamente piezas singulares, concentrándose estas en capiteles, fustes y basas. Así, en la basílica de San Salvador de Valdediós (fase I ${ }^{55}$ se reutilizan todos los fustes y basas de columnas (arcos de embocadura de la cabecera y arco del vestíbulo occidental) y la pareja de capiteles de los ábsides laterales. El pórtico, añadido a esta primitiva obra, prescinde de materiales de aporte. Pero las observaciones de Valdediós pueden extenderse, al menos con seguridad, a los ejemplos ya citados de Lillo, Tuñón y Santullano. En ninguno de ellos puede hablarse de material constructivo reutilizado, sino exclusivamente de columnas (a veces excluyendo los capiteles).

En la basílica de San Miguel de Escalada (León), de nuevo encontramos piezas de origen romano (basas, fustes y parte de los capiteles y cimacios del aula) empleadas sin apenas reelaboración. Escalada demuestra cómo los elementos singulares de aporte suplen las carencias de los talleres que trabajan en el edificio y ayudan a administrar esfuerzos: mientras el arco transversal meridional se asienta sobre una imposta que reutiliza una pieza romana fragmentada en dos, el parejo septentrional lo hace sobre una imposta tallada para tal efecto. Es decir, la presencia de talleres puede implicar un menor empleo de materiales reutilizados, pero no significa su desaparición, sino su adecuado empleo ${ }^{56}$. A diferencia de Valdediós, en el pórtico de Escalada, también de un segundo momento, se reutilizan basas y fustes, no así capiteles. El mismo patrón se identifica en San Cebrián de Mazote (Valladolid), con un modelo de combinación de materiales nuevos y expoliados que reproduce el primer momento de Escalada.

Tanto los ejemplos asturianos como los castellanos tienen en común la no fabricación de nuevos fustes. Parece que no hay canteros con conocimiento, o instrumental necesario, para elaborar este tipo de piezas ${ }^{57}$. Allí donde se ven forzados a realizarlos, tanto en la embocadura central de Escalada, como también en Lourosa ${ }^{58}$, el resultado es un fuste tosco, en realidad falso, al tratarse en ambos casos de sillares parcialmente

54 I. SASTRE DE DIEGO, op. cit., 2010.

55 M. Á. UTRERO, op. cit., 2012.

56 En Escalada y en Valdediós (aquí anotado por C. GARCÍA DE CASTRO, "La escultura arquitectónica en el área central del reino de Asturias: tipos, tradiciones y tendencias", L. CABALLERO y P. MATEOS (eds.), Escultura decorativa tardorromana y altomedieval en la Península Ibérica, Anejos de AEspA 41, Madrid, 2007, pp. 85-132, p. 113) los capiteles reutilizados están solo en las embocaduras de los ábsides laterales, siendo nuevos en el central. Fuera de este hecho, no se puede concluir un patrón de reutilización de las piezas según un significado simbólico de su uso.

$57 \mathrm{M}^{\mathrm{a}}$. Á. UTRERO, op. cit., 2012.

58 Reubicados en la restauración del siglo XX: M. Á. UTRERO, Análisis arqueológico de la iglesia de São Pedro de Lourosa (Oliveira do Hospital, Coimbra), Portugal, Informe manuscrito, IH-CCHS, Madrid, 2009. 
tallados que insinúan fuste y jamba en una misma pieza ${ }^{59}$. En los ejemplos asturianos, los fustes son en realidad sillares murarios tallados de modo curvo y aparejados para dar lugar a parejas de columnas, como en Santa María del Naranco, o únicas, como en Santa Cristina de Lena, pero nunca fustes monolíticos.

\section{OBSERVACIONES FINALES}

La reutilización de materiales forma parte del ciclo constructivo como una fuente más de recursos para la consecución de determinados elementos. En la Península Ibérica hay varios ejemplos de ello, con edificios que demuestran que los materiales reutilizados y las innovaciones tecnológicas convivieron en un mismo proyecto edilicio. Se valoraron las posibilidades y la rentabilidad de los materiales como reutilizables, su proximidad geográfica y su adaptabilidad para reconvertirlos funcionalmente. Esta realidad contradice la habitual asociación del reempleo de materiales con la escasez de recursos económicos. Una vinculación que hizo fácil y exitoso establecer una correlación de hechos históricos como explicación de tal fenómeno: crisis de la ciudad desde el Bajo Imperio $=$ decadencia y abandono de las construcciones $=$ aparición del hábito del expolio. Pero no es cierto que la reutilización sea siempre sinónimo de pobreza. Especialmente irónico resulta una interpretación de este tipo en el caso de Constantino, promotor de numerosas obras, casi todas ex novo, incluso fundador de una nueva ciudad en un tiempo además de florecimiento de los talleres de escultura funeraria. Cuando se reutiliza, como en su arco triunfal de Roma, no es por una situación de declive global e irreversible, sino por una pérdida de la habilidad requerida para producir un elemento concreto (grandes relieves en este caso), los cuales seguían siendo sin embargo elementos apreciados y a veces solicitados ${ }^{60}$.

En muchas ocasiones, la reutilización tampoco es sinónimo de ahorro de costes, no al menos al nivel que se cree. Durante el ciclo productivo pueden darse hasta tres tipos de incremento del gasto económico del proyecto por el uso de expolios, y los tres pueden concurrir a la vez: el proceso de extracción, la distancia-transporte del material y su reelaboración y ajuste en la obra. Estos factores son a su vez variables que pueden informarnos sobre quiénes fueron los comitentes, qué intereses tuvieron, sus posibilidades económicas y sus necesidades. Por ejemplo, la decisión de conseguir ciertos materiales singulares de procedencia lejana pudo estar motivada por el deseo de obtener objetos de diferenciación y prestigio que lo destaquen de las construcciones vecinas, hecho que a la vez conlleva un mayor gasto ocasionado especialmente por los costes del transporte. Otras veces fue la falta de pericia en la talla de algunos materiales lo que provocó la búsqueda de piezas antiguas. Esto es lo que parece ocurrir con los elementos de forma cilíndrica. La ausencia de fustes y basas producidos ex novo demuestra

59 M. GÓMEZ MORENO, Iglesias mozárabes. Arte español de los siglos IX al XI, Madrid, 1919, p. 146, describe las de Escalada como jambas con fustes incorporados y las compara con las de "Melque y Asturias".

60 B. WARD-PERKINS, "Re-using the Architectural Legacy of the Past, entre Idéologie et Pragmatisme", G. P. BROGIOLO y B. WARD-PERKINS (eds.), The Idea and Ideal of the Town between Late Antiquity and the Early Middle Ages, The Transformation of the Roman World 4, Leiden, 1999, pp. 225-244 (p. 232). 
una incapacidad técnica para tallar piezas cilíndricas, no existen o no se dominan los instrumentos necesarios para trazar y crear estas formas. Sin embargo, sí hay capiteles labrados ex profeso, piezas que forman parte de la columna pero con otra forma de talla, en paralelepípedo o troncopiramidal, que requiere del uso de instrumental diferente. La inexistencia de columnas ex novo parece refrendar el cese de la explotación de las canteras naturales y su sustitución por todo tipo de expolio, lo que provocaría la necesidad de un mercado activo atendido por talleres ambulantes con expertos en desmontes, con ciertos conocimientos de cantería y carreteros. Este mercado no se dedicaría solo a columnas, sino a todo tipo de material. También debemos subrayar que el valor de las columnas de mármol no reside únicamente en su calidad o belleza, sino en el hecho de que no se producen ${ }^{61}$. Son estas posiblemente el gran indicador del cese de las canteras en esta época: mientras otros materiales pueden extraerse en superficie, el mármol solo puede obtenerse por medio del expolio.

Aún son muchas las cuestiones abiertas que merecen ser analizadas con profundidad en el futuro y no solo por la Arqueología. Es el caso de los protagonistas en el ciclo de la reutilización, partiendo de quién era propietario y quién podía hacer uso de las canteras y/o edificios-cantera. Propiedad, régimen de explotación y rentabilidad son preguntas, entre otras, todavía por responder ${ }^{62}$. Suponemos que las competencias de las que fueron de propiedad imperial pasarían a los gobiernos de cada nuevo reino surgido del antiguo imperio de Occidente. A su vez, en aquellas que pertenecieron a los municipios ${ }^{63}$, el uso de tales recursos, probablemente ahora como material reutilizable, estaría controlado por los obispos de las ciudades. Pero esta hipótesis está por estudiar.

Los datos y reflexiones aquí expuestos abren, en nuestra opinión, una nueva perspectiva que pretende introducir el fenómeno de la reutilización de materiales en el proceso de análisis y comprensión de la puesta en marcha y desarrollo de los proyectos constructivos en la Tardoantigüedad y el Altomedievo. Nueva información permitirá en un futuro próximo ir respondiendo a las cuestiones aquí presentadas junto a otras aún seguramente por plantear.

61 D. KINNEY, "Roman Architectural Spolia", Proceedings of the American Philosophical Society 145-2 (2001), pp. 138-150 (p. 146); y G. BINDING, Vom dreifachen Wert der Säule im frühen und hohen Mittelalter, Sitzungsberichte des Sächsischen Akademie der Wissenschaften zu Leipzig. Philologisch-historische Klasse, Band 138, Heft 2, Leipzig, 2003, p. 7, recoge numerosas referencias documentales de épocas alto y bajomedieval en las que se menciona el esfuerzo de los comitentes por obtener columnas de mármol, las cuales se citan frecuentemente como preciado elemento. Para Asturias, la Crónica Albeldense (J. GIL, J. L. MORALEJO y J. I. RUIZ DE LA PEÑA (eds.), Crónicas Asturianas, Oviedo, 1985, 174.9) especifica que todas las iglesias construidas por Alfonso II (791-842) tenían columnas de mármol.

62 B. WARD-PERKINS, From Classical Antiquity to the Middle Ages. Urban Public Building in Northern and Central Italy. AD 300-850, Oxford, 1984, pp. 204-205, la documentación escrita para la ciudad de Roma permite constatar un paulatino traspaso del control de los edificios en desuso y susceptibles de ser fuente de materiales constructivos desde manos imperiales, con una legislación (458) acorde que protegía tanto la propiedad del edificio como la adquisición del material, a las posteriores autoridades episcopales.

63 Como se ha propuesto para las canteras de brocatello con Dertosa o para las de Ampurias y Barcelona: A. GUTIÉRREZ GARCÍA-MORENO, "Canteras del noreste de Hispania (actual Cataluña): propuesta de cronología y consideraciones generales”, T. NOGALES y J. BELTRÁN (eds.), Marmora Hispana: explotación y uso de materiales pétreos en la Hispania romana, Roma, 2008, pp. 166-195. 